\title{
The Causes of Global Climatic Changes: International and Environmental Law Perspective
}

\author{
*Themba Mathebula LLB, LLM (UL) \\ Lecturer Faculty of Management and Law, University of Limpopo, School of law \\ Email: Themba. Mathebula @ul.ac.za
}

\section{Doi:10.5901/mjss.2014.v5n23p451}

\begin{abstract}
The article investigates problems involved with the causes in climate changes. Environmental law will be used to canvass possible reduction of these changes. The South African Constitution and International instruments will be consulted. The existing international agreements, such as the Kyoto Protocol, have not been adhered to and need ratification. A treaty is not enforceable until ratified. The results show that, the main contributors to the major cause of this climate change are the signatories to the Kyoto Protocol. The problem also lies in countries with larger industries involved in the greater emission of green gases. At the end, an advanced framework for the reporting of emission minimisation for both developed and developing countries need to be effected, taking into consideration the common but differentiated responsibilities for each country.
\end{abstract}

Keywords: climate change, contributions and causes, recognition and compliance, ratification, lack of compliance, intervention, challenges and way forward

\section{Introduction}

This article will indicate some elements of environmental law on climate changes and natural aspects that existed for a long time and other factors that contribute for the development of this law. Environmental law and climate changes are being considered as the combination of various areas of law such as energy law, business law, and international law, as well as Administrative law. When addressing issues of climate change, the various resolutions from different states coupled with treaties will be of immense value. In this article, some contributory factors such as green gases and their causes in as far as climate change are concerned will be addressed and what applicable law will best help in addressing this global challenge, including the use of local and foreign law.

Climate changes impacts are already affecting people and the planet. Research shows it will get far much worse in the near future. The biggest impacts will be on the lives and livelihoods of the poor in developing countries. The poor are more vulnerable than the rich for several reasons. Flimsy housing, poor health and inadequate health care mean that natural disasters of all kinds hurt them more. The biggest culprits are the rich and the developed countries.

\section{Climate Change Defined}

The definition of climate change depend an individual knowledge. At most, it is believed that it is a change in world's climate. The common definition of climate change is; a change in the state of the climate that can be identified by changes in the mean and/or the variability of its properties, and that persists for an extended period, typically decades or longer. It refers to any change in climate over time, whether due to natural variability or as a result of human activity (IPCC: International Plant Protection Convention (2007))

\section{Contributions and Causes to Climate Change}

The world believes that, the causes of climate changes are forms of industrial emissions and or of greenhouse gases. We, humans are also the contributors of climate change, thus, the constant use of heat which is coupled with smoke emissions and other various emissions such as chemical-including gases emissions. The use of high energy level at households contribute mainly to the cause of changes in atmospheric temperatures and ultimately, climatic changes. The Kyoto Protocol signatories to the reduction in climate change are still today, the major contributors or polluters of the atmospheric weather and thus experience severe and extreme weather changes and patterns. The uses of heavy 
machines in industries which are common to greenhouse gases are the most contributors and thus there is a need for change in operation, such as to opt for lighter-energy utilising machinery. Burning most phases of matter also bring about the change in climate, like the burning of coal, coal refinery processes, chemical experiments and controls and the smelting of certain minerals or products. There should be some legislation adopted, internationally and nationally, to support the international treaties or agreements on the reduction or bringing about the minimisation in climatic changes. So, the cause of climate changes is mainly human than natural.

Some say; Carbon dioxide (CO2) and other greenhouse gases (GHG) produced by the burning of fossil fuels and forests and other anthropogenic activities are accumulating in the atmosphere and causing average global temperatures to rise - a phenomenon termed 'Global warming'. The resultant climate change raises complex legal and technical questions related to the environment, and to science, economics, rights and development (Dan Kuwali: From the West to the rest: Climate change as a challenge to human security in Africa: African Security Review 17.3 Institute for Security Studies)

Some other major causes have been identified on three spheres of government. i.e. National, provincial and local (Governance on climate change in South Africa: a report by the department of Environmental Affairs (2011)). Each of these spheres has been considered to have its own environmental departments or line functionaries ((Kotzé, 2006).), who then are responsible for a direct result of government decentralisation in South Africa. To thus far, research shows that, the delegation of environmental functions to the lowest possible level has placed increasing responsibilities on local government. This then leads to an expanded role from mainly service provision to that of an active development agent (Kotzé, 2006). Contrary to its intentions, recent reports have shown an increase in greenhouse gasses, with the power supply sector being responsible for a majority of the emissions. There is need to minimise emissions by approximately $90 \%$ in order to delay the effects of climate change and achieve the desired minimization.

The Section 24 of the South African Constitution has made it clear that, everyone has a right to a healthy environment. That is, an environment that is free from harm to wellbeing. Lately, Eskom is on the urge of increasing electricity, without due consideration of the preservation of the environment. They are largely concentrated on the price and interest hikes rather that making mechanism of minimising the great emission of green gases during the period of manufacturing electricity. Research shows that Eskom is one amongst the industrials on the list of high polluter which also contribute to cause the change in climate. The degradation of the environment by companies like Eskom has thus far led to severe temperature increases and greater impact on environment than there was before. These are as a result for their open casted environmental exposure that they embark on day to day, like the use of coal in manufacturing electricity. The use or release of carbon monoxide (CO) by these industries at a high rate has led to the greater and severe impact on environmental health. This happens because the coal or oil burning process combines carbon with oxygen in the air to make Carbon dioxide. To a lesser extent, the clearing of land for agriculture, industry, and other human activities have increased concentrations of greenhouse gases.

Environmental right is a human right. Many countries had developed this concept that environmental right is a human right, and thus it needs to be preserved. Thus far if this environmental human right continue to be violated, there is a need for formal policies or passing of specific international legislations to put this to an end. The issue of causes of change in climate is an environmental issue and need an international environmental law intervention in a form of legislation.

\section{The Need for Recognition for Compliance and Enforcement}

This is a common concept in South Africa where there is possible environmental impact, such as in municipal and provincial government which often have considerable authority. Sometimes these extends to legislation, planning and investment decisions including those related to climate change. In addition, committed local government can play an important role in supporting behaviour change among its citizens. National Environmental Management Act (NEMA) requests the design of environmental implementation plans (EIPS) and environmental management plans (EMPs) by state bodies, including provinces, while Section 46 gives municipalities the power to prepare by-laws to implement the Act. Some municipalities are ahead of national government in regulating climate change impacts with metros like Durban, Cape Town and Johannesburg having climate change programmes. Consequently, the different spheres of government have to be involved as early as possible in the policy making process. Policy changes are necessary for combatting climate change and if this is not done there will be buy-in from these key players who will turn the world's policies to run a high risk of being ineffective.

The provincial and local spheres of government are regarded as the "implementation arms of the national government" and their resources and skills directly influence the effective and efficient enforcement and implementation 
of the environmental legislative framework .Provincial government has an important function in setting provincial norms and standards, and in assisting local governments to meet their obligations including managing and protecting the environment. In turn, national government has an obligation to assist provincial governments in implementing their constitutional and legal executive obligations, functions and missions, which include assisting municipal governments. Provincial and local governments have experienced constraints that "interfere with the countrywide enforcement and implementation of environmental policy". This highlights the fact that the current institutional structure and the lack of capacity pose a challenge to the delegation and decentralisation of executive environmental functions to the most appropriate level. The main challenge seems to be that "implementation failure at local level limits the effective functioning of the environmental governance framework" (DEAT, 2006,75)

It is in this institutional context, chiefly framed by the Constitution, NEMA, the IGRA and other Acts related to the functioning of local government, such as the Municipal Financial Management Act, No. 56 of 2003 (MFMA) or the Municipal Systems Act, No 32 of 2000, that the vertical coordination system has to be developed. The fragmentation resulting from this governance structure can be termed "structural fragmentation" a phrase, which describes separate, disjointed line functions in and across all three spheres of government (Kotzé, 2006). This Conference of the Parties is crucial as an agreement will have to be reached on how to achieve reduction in emissions by both developed and developing nations while taking into consideration the specific needs of the developing nations.

Promises and good intentions are not enough - its goals will have to be achieved in order for South Africa to set a concrete example to other developing nations. The battle between environmental protection and industrial development is raging in the face of the undertakings made by government, illustrated by a recent comment by Planning Minister, Trevor Manuel, speaking at a climate finance seminar, who stated that South Africa was not to abandon its labour-intensive industries in pursuit of its climate change mitigation targets. Though there is global recognition of the problem, developing nations need to assess the wisdom of their approach of putting the need for current industrialisation and growth above that of climate change mitigation. Though the concern that their development will be impeded compared with the already developed nations is legitimate, it must be understood that this is a global concern.

In his article, Dale Tladi (Naidoo is an associate, Environmental Practice, Cliffe Dekker Hofmeyr. The article was reviewed by Helen Dagut, Senior Associate, Environmental Practice) embraces that; he has, in other publications, criticised the Kyoto Protocol on the grounds that environmental and social concerns in the Protocol are sacrificed for economic concerns. The assertion that those, involvement of private entities in the flexible mechanisms are not vulnerable to the attacks against private entity involvement does not in any way contradict these earlier conclusions. These earlier conclusions were based on aspects of the Protocol other than the role of the private entities, in particular the flexible mechanisms per se, the low targets as well as the manner in which the intergenerational equity is reflected in provisions of the Protocol. These factors, in my view, reflect the dominance of economic concerns. What is suggested here, however, is that the involvement of private entities in the climate change regime is justifiable because, first, the standard of the regulation is not left up to the entities but is determined in the Protocol. Second, the ultimate responsibility for the performance of the obligations in the Protocol remains that of the states.

\section{The Ratification Process Agreements (International) on Climate Change}

Contribution in this section of paper will also be based on the United Nations Framework Convention on Climate Change (Entered into force on 21 March 1994). The United Nations Framework Convention on Climate Change (UNFCCC or FCCC) is an international environmental treaty produced at the United Nations Conference on Environment and Development (UNCED), informally known as the Earth Summit, held in Rio de Janeiro from June 3 to 14, 1992. The objective of the treaty is to stabilize greenhouse gas concentrations in the atmosphere at a level that would prevent dangerous anthropogenic interference with the climate system.

The treaty set no mandatory limits on greenhouse gas emissions for certain countries and contains no enforcement mechanisms. In that sense, the treaty is considered legally non-binding. Instead, the treaty provides for updates (called "protocols") that would set mandatory emission limits. The principal update is the Kyoto Protocol, which has become much better known than the UNFCCC (The UNFCCC was opened for signature on May 9, 1992, after an Intergovernmental Negotiating Committee produced the text of the Framework Convention as a report following its meeting in New York from April 30 to May 9, 1992. It entered into force on March 21, 1994. As of May 2011, UNFCCC has 194 parties.) One of its first tasks was to establish national greenhouse gas inventories of greenhouse gas (GHG) emissions and removals, which were used to create the 1990 benchmark levels for accession of Annex I countries to the Kyoto Protocol and for the commitment of those countries to GHG reductions. Updated inventories must be regularly submitted by Annex I countries. 
Annexure I was adopted as sort of an international binding agreement on these countries to commit in the reduction towards climate changed. Thus it involved them to be accountable, supportive and also plan for these reductions. It is in this Annexure that developed countries were to reduce their greenhouse gases as seen to be the largest contributors towards change in climate.

The parties to the convention have met annually from 1995 in Conferences of the Parties (COP- The Conference of the Parties is the governing body of the Convention, and advances implementation of the Convention through the decisions it takes at its periodic meetings) to assess progress in dealing with climate change. In 1997, the Kyoto Protocol was concluded and established legally binding obligations for developed countries to reduce their greenhouse gas emissions. "The agreement is subject to ratification, and its ultimate success depends on whether national governments can sell it back to the parliaments and lawmaker" which was written by Robert Watson, Director, Environment Department , World Bank, and Chairman: Intergovernmental Panel on Climate Change, discussing the Kyoto Protocol

The ratification of a treaty is such an important part in most cases where there is lack or absence of knowledge in as far as adoption of possible measures is concerned in reduction of climate change. Thus, there are countries that are immune or rather common in delaying some of the treaties ratification processes and thus leading to feather change in climatic conditions. The cause is their fear of either their presumed tariffs of costs or lack of resources which in turn are relevant for contribution in ratifying treaties. "Global environmental policies carried out by international treaties suffer from a least two drawbacks:

$>$ First, since participation is voluntary for each sovereign state, both in the ratification and compliance stages, an international environmental agreement is based on consensus of all participants and must be selfenforcing.

$>$ Second, ratification of an international environmental treaty by parliament results in a time lag, delaying the implementation of the provisions of treaty by PER G FREDRIKSSON and NOEL GASTON: Ratification of the 1992 Climate Change Convention: What Determines Legislative Delay?

States can participate fully or dedicate some much needed time to the international treaties in reducing factors contributing to climate change. There can be not much left to fix but little to develop. It is every country's baby to feed and to nourish where drastic climate changes are concerned. Working as one in all global dimensions the more can be reached and achieved. The most common aspect or emergence that international society can divulge is to help in contributing positively towards ratifying treaties where there is no possible development on such treaties, preventing possible or further unbearable climate changes.

Developed states should also participate to help improve policy development and compliance on this aspect of climate change and in fixing the delay in amending treaties in developing and under-developed states. Policy directives must be considered the most aspects to be contributed and submitted during international treaties and debates thus leading to major or minor ratification where necessary. Usually, it is a problem with developed countries (signatories to Kyoto Protocol) when coming to needed support to reduce climate changes. This is also where most countries fail support to contribute to the possible solutions to amend the older treaties. These then fall short of adjustments to current global development in terms of technologies and industrial operations. Sometimes lack of compliance by member states in assisting to promote or adopt possible measures to reduce certain or common factors, such as green gases, often contribute to the fluctuate changes in climate. This leads to lack of global participation and as a result, to less interest in ratifying possible lacunas in current or existing agreements.

\section{Lack of Compliance}

Climate change impacts are the problems of the world and as such are affecting everyone. The most affected, however, are the developing countries or countries with less power. These change impacts negatively on the developing countries' lives and available resources. Developing states are exerted with pressure to maintain and preserve their environment and impact that the changes in climatic conditions might have to them, though with limited resources.

There are international agreements which involve more resources for scientific research, leading to stronger evidence; some policy advances; a change in industry rhetoric; and a certain increase in public awareness. At the heart of the problem is the production and use of fossil fuel, particularly the emissions of carbon dioxide from the burning of coal, oil and gas. Developed countries have now accepted legally-binding emissions targets in the Kyoto Protocol, but these are seriously inadequate. As Klaus Töpfer (Ibid) says, there are laws in place now that can address this. Over the last few years, many kinds of legal action have been taken around the world to enforce the law to combat climate change. A range of national and international legal theories have been invoked by dozens of different organisations, communities and individuals, such as human rights law, constitutional law, emission control regulation, endangered species protection, 
freedom of information and international legal obligations.

Scientific and economic consensus increasingly points to the need for a credible and cost-effective approach to address the threat of global climate change, but the Kyoto Protocol to the U.N. Framework Convention on Climate Change appears incapable of inducing significant participation and compliance. We find that those approaches that offer cost-effective mitigation are unlikely to induce significant participation and compliance, while those approaches that are likely to enjoy a reasonably high level of implementation by sovereign states are sorely lacking in terms of their anticipated cost effectiveness. Much more attention needs to be given to both by scholarly research and by international negotiations to aspects of future international climate agreements that will affect the degrees of participation and compliance that can reasonably be expected to be forthcoming.

The Kyoto protocol, rather the Convention's ultimate objective is to stabilise the use of greenhouse gas concentrations in the atmosphere to a level that would prevent any adverse effects to the climate system and to achieve this within a time frame to allow for the natural adaptation to climate change in a sustainable manner. Sustainable development is key to the Convention. The Convention provides a basic framework including goals. The details of how and by when the goals are to be achieved are contained in the Kyoto Protocol, which was adopted in 1997(Sahndya Naidoo: "Agreement after Kyoto?). A well-known example is a debate in Inuit (a group of culturally similar indigenous peoples inhabiting the Arctic regions of Canada) people of North Alaska, Canada, Greenland and Russia against the United States at the Inter-American Commission on Human Rights. They claimed that by being responsible for the world's highest level of Carbon dioxide emissions and by not participating in the Kyoto Protocol, the United States was to blame for the losses the Inuit suffer due to climate change. Their traditional way of life is changing completely due to extreme global warming in this region. Its effects mean the animals living on the ice - the Inuit's main food source - are disappearing along with the ice. Their claim was rejected, but it did open up the discussion on this and related issues (South Africa: Climate Cases Surge - Time for a Climate Court? 9 December 2011(DURBAN, RSA)).

The South African authorities were setting up special courts in the port city of Durban in its preparation for the Nov. 28 to Dec. 9 United Nations climate change talks. These special courts were to be on standby 24-hours a day to deal with climate change conference-related crimes, according to the South African Press Association (SAPA). It was reiterated that South Africa wants to deal with criminals in the same way as it did during the FIFA 2010 World Cup, when the process was praised for its swiftness and efficiency.

\section{International Law Intervention on Climate Change}

Climate change in most countries is been targeted towards most gas substances and major other aspects on various commodities which have an impact of emissions of these gases. An international law is a major aspect in this regard which governs the relationship between established rules and standards to be adopted in rectifying these climatic changes. Proper application of international law often leads to legal arguments as between states where there is an alleged breach of international obligation. There is a newly rule debated most at international level, thus the "no-harm" rule. This is worldwide principle of international customary law where each country is tasked with the duty to prevent, reduce and control the risk of environmental harm to other states. This rule has subsequently been entertained by few international courts (Mike McCarthy and Ben Ferguson, 'Hopes of global emissions deal at Copenhagen begin to fade', The Independent, London 14 December 2009). It was also used in various international law and policy directives. The principle, thus principle 21 of the 1972 Stockholm Declaration provides that "States have, in accordance with the Charter of the United Nations and the principles of international law, the sovereign right to exploit their own resources pursuant to their own environmental policies, and the responsibility to ensure that activities within their jurisdiction or control do not cause damage of the environment of other States or of areas beyond the limits of national jurisdiction." This principle of "no-harm" rule can be exercised in international law based on due diligence. It means the ability to prevent harm that a certain act can lead to severe damages and thus must be prevented. The international judicial intervention must also play a role here in form part of global negotiations as far as climate change is concerned.

The challenges of international environmental regulation have opened up anew avenue for increased participation of non-state actors in international law. As has been noted, while international law is primarily addressed to state conduct, environmental harm is caused primarily by private activities. The impact of globalisation in this regard has been to increase the negative environmental externalities of economic activity (Dire Tladi: BLC LLB (Pretoria) LLM (Connecticut) PhD (Erasmus University Rotterdam), Principal State Law Adviser, for International Law, South African Department of Foreign Affairs). The views expressed in this article are those of the author and do no necessarily reflect the views of the Department of Foreign Affairs or the Government of the Republic of South Africa. 1See, eg, Ratner 'Business' in Bodansky, Brunnée and Hey (eds) The Oxford handbook of international environmental law (2007)). 
The relevance of non-state actors in modern international law (and international environmental law in particular) and how this impacts on current understanding of international law has been the subject of much research in recent times. What is clear from the work that has been done thus far is that the role of non-state actors in the regulation of international environmental law involves several aspects. For one thing, the regulation versus deregulation-and-the-useof-market-mechanismsto-achieve-environmental-goals debate is premised on the capacity of non-state actors (and business in particular) to effectively self-regulate to the benefit of the environment. Second, more and more non-state actors are actively involved, in different ways, in the creation of international environmental law rules (Wiener 'Global environmental regulation: Instrument choice in legal context' (1999) 108 Yale Law Journal 677, also in various essays in Bosselmann and Richardson (eds) Environmental justice and market mechanisms: Key challenges for environmental law and policy (1999).

\section{Challenges}

One of the most common challenges between states is lack of consensus or compliance in terms of treaties. States will voluntarily enter into treaties, and subsequently dishonour them. Major concentration to this aspect of lack of compliance or consensus inter partes, occurred in the Kyoto Protocol, where member-states where major signatories to the treaty itself, and eventually failed to honour its resolutions. This, in a way, leaves open the question as to whether parties had really an impeachable agreement which will tie parties to adherence or it was just a matter of formality, of which formality cannot be waived later.

The commitment to reduce emissions by at least $5 \%$ is a commitment undertaken by the Annex (Of the Kyoto Protocol (1990)) states collectively, and being a commitment undertaken by states, does not depart from the traditional concept of international law. The same can be said of the individual commitments undertaken by states to limit their anthropogenic emissions to their assigned amount units. It is these individually assigned amount units that make up the overall $5 \%$ reduction commitment. What is interesting to note, however, is that while the state is the primary addressee of the obligation in article 3, it is ultimately private entities that will have to act to ensure compliance with this obligation. In this sense it is noted that the duty of the state is more akin to that of a facilitator. Thus, article 2 of the Protocol provides that the state 'in achieving its' obligations under article 3 shall 'elaborate policies' on, inter alia, 'energy efficiency in relevant sectors', 'sustainable forms of agriculture' and the 'development and increased use of ... renewable forms of energy'.

The involvement of the private entities is also considered one of the major contributions that may be needed to the possible reduction. The role of non-state actors in climate change regulation, and corporate entities in particular, is reflected in various ways in the Kyoto Protocol. First, the Protocol allows private entities to participate in the flexible mechanisms. Second, while the Protocol imposes quantified emissions reduction and limitation obligations (or commitments) on states ultimately it is the private entities that must reduce emissions set in the Protocol. The role of the state is to encourage and facilitate (or require) reduction of emissions by private entities. Finally, the Protocol protects private entities involved in trade through its provision against trade protectionism (Article 3(1) provides as follows: The Parties included in Annex I shall, individually or jointly, ensure that that their aggregate anthropogenic carbon dioxide equivalent emissions [greenhouse gases] do not exceed their assigned amounts ... with a view to reducing their overall emissions of such gases by at least 5 per cent below 1990 levels).

The increased role of private entities is further reflected in the protection afforded to trade in the Kyoto Protocol. Article 2(3) of the Protocol provides that the Parties should ensure that their obligations under the Protocol are implemented 'in such as a way as to minimise adverse ... effects on international trade ...'16 In the United Nations Framework Convention on Climate Change, article 3(5) provides that measures taken in response to climate change 'should not constitute a means of arbitrary or unjustifiable discrimination or a disguised restriction on international trade'. This protection of international trade (and economic interests generally in the Protocol) reflects the increased role of private entities in two ways. First, and this links up the previous point, it is generally private entities that trade and not governments. Governments may facilitate trade and create conditions conducive to free trade but, as a rule, they do not themselves engage directly in trade. It is for this reason, for example, that the Cartagena Protocol on Biosafety to the Biodiversity Convention does not impose obligations on the state but rather on the exporter.

\section{Way Forward}

There has to be radical change in the geo-political world in the next decades, with some developing countries now being major economic and political players, who also need to be taken into account, leading to a new balance of power and 
influence, entailing new roles and new responsibilities.

The European countries must face critical choices to preserve their future prosperity and security, and at the same time moving to a domestic greenhouse gas emissions reduction target which will be in line with the EU's climate objectives that can be combined with a healthier economy, and an increase in green jobs and innovation;

There has to be more preservation of wild \& life to $70 \%$ worldwide and of which percentage must ultimately be able to adapt, and more vulnerable, to climate change; whereas Article 7 of the Cancun Agreements stresses that 'gender equality and the effective participation of women and indigenous peoples are important for effective action on all aspects of climate change',. Yes it is important for the disadvantaged to also play part in preserving or make favourable the conditions towards climate change thereby reducing the factors contributing as such.

The substantial differences in scope, structure and design which exist between Land Use, Land-Use Change and Forestry (LULUCF) reporting under the UNFCCC Convention and LULUCF accounting under the Kyoto Protocol, undermining Parties' climate change mitigation efforts must be overlooked to resort amicable solutions to some point. Thus, in general it is the participation of everyone to contribute to the effort of making, or ensuring the reduction in climate changes. There can be no contribution towards change if there is no development.

\section{Conclusion}

It is clear that (international) environmental law on climate changes is being considered to be of major significance to existing laws. Issues of climate change, the various resolutions from different states coupled with treaties are of immense value as far as correcting of environmental and climatic conditions are concerned. In this article, some contributing factors as far as climate change is concerned were addressed and applicable law in helping to address this global challenge.

The ratification of a treaty plays an important part in most cases where there is lack or absence of knowledge in as far as adoption of possible measures is concerned in reduction of climate change. Thus, countries must be taught about procedures which will not delay treaties ratification processes and thus leading to reduction in climatic conditions. The cause of delays is considered to be their fear of either presumed tariffs of costs or lack of resources which turn out to be relevant for contribution in ratifying treaties. Courts must also play a major role in applying the international law rules and standards in as far as factors contributing to climate change are concerned; thus to reduce or minimise these changes, which in turn must lead to states participation and compliance.

\section{References}

IPCC: International Plant Protection Convention (2007).

Dan Kuwali: From the West to the rest: Climate change as a challenge to human security in Africa: African Security Review 17.3 Institute for Security Studies

Governance on climate change in South Africa: a report by the department of Environmental Affairs(2011)

Kotzé, 2006.Fakier et al., 2005 Act 108 of 1996, hereinafter referred to as a the Constitution

Naidoo is an associate, Environmental Practice, Cliffe Dekker Hofmeyr. The article was reviewed by Helen Dagut

Ratner 'Business' in Bodansky, Brunnée and Hey (eds) The Oxford handbook of international environmental law (2007) Entered into force on 21 March 1994m

Robert Watson, Director, Environment Department, World Bank, and Chairman: Intergovernmental Panel on Climate Change, discussing the Kyoto Protocol

Per G Fredriksson and Noel Gaston: Ratification of the 1992 Climate Change Convention: What Determines Legislative Delay?

Sahndya Naidoo: "Agreement after Kyoto? a group of culturally similar indigenous peoples inhabiting the Arctic regions of Canada.South Africa: Climate Cases Surge - Time for a Climate Court? 9 December 2011(DURBAN, RSA)

Mike McCarthy and Ben Ferguson, 'Hopes of global emissions deal at Copenhagen begin to fade', The Independent, London 14 December 2009.

Dire Tladi . Wiener 'Global environmental regulation: Instrument choice in legal context' (1999) 108 Yale Law Journal 677- also in various essays in Bosselmann and Richardson (eds).

Environmental justice and market mechanisms: Key challenges for environmental law and policy (1999) Of the Kyoto Protocol (1990) Article 3(1)

Robert Watson, Director, Environment Department, World Bank, and Chairman: Intergovernmental Panel on Climate Change, discussing the Kyoto Protocol.

Kyoto Protocol to the U.N. Framework Convention on Climate Change 1992

United Nations Framework Convention on Climate Change, Rio de Janeiro from June 3 to 14, 1992

Article 7 of the Cancun Agreements: The agreements, reached on December 11 in Cancun, Mexico, at the 2010 United Nations Climate Change Conference.

South African Press Association: (The agency was established on July 1, 1938,[1] by major South African newspapers to facilitate the 
sharing of news), December, 2011

South Africa: Climate Cases Surge - Time for a Climate Court? 9 December 2011(DURBAN, RSA)

LULUCF: Land Use, Land-Use Change and Forestry: United Nations Framework on Climate Change

International climate change litigation and the negotiation process( Foundation for International Environmental Law and Development), October 2010

Dan Kuwali: From the West to the rest: Climate change as a challenge to human security in Africa: African Security Review 17.3 Institute for Security Studies. IPCC: International Plant Protection Convention (2007).

Journal of Human Rights and the Environment ;Kotzé, 2006

Fakier et al., 2005, Cliffe Dekker Hofmeyr

The article was reviewed by Helen Dagut, Senior Associate, Environmental Practice BLC LLB (Pretoria) LLM (Connecticut) PhD

(Erasmus University Rotterdam), Principal State Law Adviser, for International Law, South African Department of Foreign Affairs.

Ratner 'Business' in Bodansky, Brunnée and Hey (editions) The Oxford handbook of international environmental law (2007)

The UNFCCC was opened for signature on May 9, 1992, after an Intergovernmental Negotiating Committee produced the text of the Framework Convention as a report following its meeting in New York from April 30 to May 9, 1992 It entered into force on March 21, 1994. As of May 2011, UNFCCC has 194 parties.

Wiener 'Global environmental regulation: Instrument choice in legal context' (1999) 108 Yale Law Journal 677

Sahndya Naidoo: "Agreement after Kyoto Volume 112011 Pages: 74 - 76.

South Africa: Climate Cases Surge - Time for a Climate Court? 9 December 2011(DURBAN, RSA.) 